\title{
Postoperative pain management in the postanesthesia care unit: an update
}

This article was published in the following Dove Press journal:

Journal of Pain Research

16 November 2017

Number of times this article has been viewed

\section{Jie Luo}

Su Min

Department of Anesthesiology, The First Affiliated Hospital of Chongqing Medical University, Chongqing,

People's Republic of China
Correspondence: Su Min

Department of Anesthesiology, The First Affiliated Hospital of Chongqing Medical University, No. I Youyi Road, Yuzhong District, Chongqing 400016, People's

Republic of China

$\mathrm{Tel} / \mathrm{fax}+862389011068$

Email ms89011068@I63.com

\begin{abstract}
Acute postoperative pain remains a major problem, resulting in multiple undesirable outcomes if inadequately controlled. Most surgical patients spend their immediate postoperative period in the postanesthesia care unit (PACU), where pain management, being unsatisfactory and requiring improvements, affects further recovery. Recent studies on postoperative pain management in the PACU were reviewed for the advances in assessments and treatments. More objective assessments of pain being independent of patients' participation may be potentially appropriate in the PACU, including photoplethysmography-derived parameters, analgesia nociception index, skin conductance, and pupillometry, although further studies are needed to confirm their utilities. Multimodal analgesia with different analgesics and techniques has been widely used. With theoretical basis of preventing central sensitization, preventive analgesia is increasingly common. New opioids are being developed with minimization of adverse effects of traditional opioids. More intravenous nonopioid analgesics and adjuncts (such as dexmedetomidine and dexamethasone) are introduced for their opioid-sparing effects. Current evidence suggests that regional analgesic techniques are effective in the reduction of pain and stay in the PACU. Being available alternatives to epidural analgesia, perineural techniques and infiltrative techniques including wound infiltration, transversus abdominis plane block, local infiltration analgesia, and intraperitoneal administration have played a more important role for their effectiveness and safety.
\end{abstract}

Keywords: postoperative complications, anesthesia recovery period, pain assessment, pain management, acute pain

\section{Introduction}

As described in the report of the Lancet Commission on Global Surgery, Global Surgery 2030 , approximately $30 \%$ of the global burden of disease can be attributed to surgically treatable conditions, and the role of surgical and anesthesia care in improving the health of individuals and the economic productivity of countries has aroused the attention of World Health Organization (WHO). ${ }^{1}$ An ultimate goal of surgical treatment is approaching better recovery for a high quality of life without complications and sequelaes. More than $80 \%$ of surgical patients experience postoperative pain, ${ }^{2}$ the undertreatment of which results in a variety of negative consequences and remains a considerable problem worldwide. ${ }^{3}$ Persistent postsurgical pain (PPP), the incidence of which being up to $30-50 \%$, originating from surgical intervention and acute postoperative pain without adequate management, has major negative effects on the individual's quality of life and places a heavy burden to the society disturbing millions of people globally and challenges for perioperative physicians. ${ }^{3-5}$ The severity of postoperative pain has been 
suggested as a key risk factor of PPP, and adequate analgesia for acute pain during the early postsurgical period may be associated with less incidence of PPP. ${ }^{3}$ Postanesthesia care unit (PACU) spans the transition from surgery room to wards, and most patients spend the first few hours after surgery, their immediate postoperative period, in the PACU. Adequate pain management in the PACU is a vital part of preventing PPP. We reviewed the recent studies for the advances in assessments and treatments for postoperative pain in the PACU.

\section{Postoperative pain in the PACU}

It was shown that $41 \%$ of patients in the PACU reported moderate or severe pain. ${ }^{6}$ Most of the patients in the PACU are characterized with a number of physiological disturbances caused by emergence from anesthesia and surgery, which affect multiple organs and systems. Postoperative pain and following agitation usually add risks and deterioration to complications with their interactions, aggravating outcomes. According to the guidelines by the American Society of Anesthesiologists, routine assessment and monitoring of pain detects complications and reduces adverse outcomes, which should be performed during emergence and recovery. ${ }^{7}$ However, unconsciousness and/or inabilities of clear verbal expression bring more difficulties in assessment and treatment for pain in the PACU.

\section{Peripheral sensitization, central sensitization, and chronification of acute postoperative pain}

Nerve injury and inflammation result in increased synthesis and release of prostanoids at the surgical site. Distal to the site of nerve injury, multiple signaling pathways promote increased nociceptive sensitivity, known as peripheral sensitization, which leads to allodynia and hyperalgesia. With prolonged painful stimulus, the dorsal horn acts as the site of central sensitization as a result of the repetitive nociceptive stimulation. In addition to chemical and genetic changes, the brainstem contributes to central sensitization by decreasing descending inhibitory modulation. ${ }^{8}$ Both peripheral and central sensitizations lead to postoperative pain hypersensitivity due to lowered pain threshold in peripheral nociceptors and increased excitability of spinal neurons, consequently resulting in PPP without timely adequate control of acute postoperative pain. ${ }^{9}$

\section{Assessment of postoperative pain in the PACU}

For better treatment and management, pain should be assessed accurately and timely, which poses challenge when concerning patients in the PACU. Although a clear description of pain should include its location, onset, character, exacerbating and relieving factors, etc., it is usually more practical to assess the intensity of pain and record time to the first analgesic usage, the amount of analgesics, the effects and adverse effects of treatment, modulation of analgesic strategies according to the response of patients, and their satisfaction in the PACU. Psychological factors influence pain perception; hence, mental status should be taken into consideration, especially for those with the history of psychiatric disorders. Identifying existed anxiety, depression, neuroticism, etc., may facilitate the assessment of pain.

There are many methods for assessing pain intensity, including observer and self-report scales. Since pain is mainly a subjective perception, the self-reporting assessment remains the gold standard for patients with consciousness, precise understanding, and verbal expression, including the Visual Analog Scale (VAS), Numerical Rating Scale (NRS), Verbal Rating Scale (VRS), and Wong-Baker Face Pain Rating Scale, although the standard method is still a topic of debate..$^{10}$ Due to uncompleted recovery from anesthesia or sedation, the results of subjective methods may be interfered by the temporary condition of the patients in the PACU (such as sedated, critically ill, cognitively impaired, or having difficulties in communicating). Therefore, objective assessment of pain and analgesia would be valuable in the PACU.

Observer-based assessment (such as Behavioral Pain Scale) can be used for objective assessment of pain. Recently, there have been more advances in novel potential objective assessments being independent of patients' participation, such as photoplethysmography (PPG)-derived parameters (assessing cardiac and vascular sympathetic response), analgesia nociception index (ANI, assessing parasympathetic cardiac response), skin conductance (SC, assessing vascular sympathetic response), and pupillometry (based on the assessment of the pupillary reflex dilatation induced by nociceptive stimulations). Most of the abovementioned methods are based on the assessment of the autonomic response to noxious stimulation indicating analgesia/nociception balance. ${ }^{11,12}$ Electroencephalogram-derived indices (such as qCON and qNOX) have also been investigated as possible predictors of patients' response to noxious stimulation under general anesthesia, which may be potentially used in the PACU, although more further studies are required. ${ }^{13,14}$

\section{PPG-derived parameters}

PPG is a sensitive indicator in reflecting blood volume change and correlated with systematic vascular resistance, which 
qualifies PPG to detect hemodynamic variables reflecting the autonomic nervous system response to pain timely. PPG can be potentially used as a surrogate to assess pain with derived parameters of which including surgical pleth index (SPI), the amplitude of alternating current $(\mathrm{AC})$ and direct current (DC) and the ratio (AC/DC), photoplethysmographic pulse wave amplitude, autonomic nervous system state (ANSS), and ANSS index (ANSSi). ${ }^{15}$ Proposed as an objective measure of the nociception-anti-nociception balance, SPI was primarily used as a monitoring tool for intraoperative pain under general anesthesia to guide analgesia, but its usage has been expanded to assess postoperative pain. ${ }^{16,17}$ It was found that SPI values were predictive of postoperative pain only if obtained before patient arousal from general anesthesia, and an SPI of 30 may be a useful predictor of moderate-tosevere postoperative pain. ${ }^{18}$ SPI could discriminate between low, moderate, and severe pain levels and was correlated significantly with total opioid consumption in the PACU. ${ }^{17}$ $\mathrm{AC}$ and $\mathrm{AC} / \mathrm{DC}$ showed significant correlations with the painrating levels, and they were found to work well in predicting pain intensity for patients in the PACU. ${ }^{16}$ Considerations for further applications of PPG-derived parameters require more evidence from studies with more homogenized experimental conditions, the comparison and choice of optimal parameter(s) from the numerous derived parameters, and the identification of optimal time points for measuring.

\section{ANI}

First used to reflect the analgesia/nociception balance during general anesthesia, ANI is calculated from heart rate variability (HRV) and has been proposed as a surrogate pain measurement, the value of which is positively correlated with parasympathetic predominance in autonomic cardiac control and has been expanded to assessing immediate postoperative pain. ${ }^{19}$ Although postoperative pain after laparoscopic cholecystectomy was not reduced by intraoperative analgesia guided by ANI monitoring, ${ }^{20}$ the measurement of ANI immediately before extubation after general anesthesia was significantly associated with pain intensity on arrival in the PACU, which can be used for the prediction of immediate postoperative pain. ${ }^{21}$ ANI measurement during the immediate postoperative period was found to be significantly correlated with pain intensity and could be used to assess immediate postoperative analgesia as well. ${ }^{19}$ However, it was reported that changes in ANI did not seem useful in differentiating between minor and severe pain, although there was a small but statistically significant negative correlation between ANI and pain after sevoflurane anesthesia in the PACU. ${ }^{22}$ Later results of the study confirmed the correlation between ANI and FLACC scale (Face, Legs, Activity, Cry, Consolability scale) in young or cognitively impaired children. ${ }^{23}$ The inconsistencies of results mentioned earlier may be caused by the different hypnotic drugs chosen for the maintenance of general anesthesia, which have different effects on HRV and the possible individual variability. ${ }^{24}$ Subsequent studies on ANI for assessing pain in the PACU need to identify appropriate proportion of patients (by excluding those taking medications affecting HRV, such as beta-blocking agents or antiepileptic drugs, and minimizing the individual variability), convert and normalize the values of ANI with the consideration of different age, awareness, and intraoperative anesthetics and analgesics received, increase the sample sizes, etc.

\section{SC}

With mirroring the bursts in the skin sympathetic nerves, which are more specific and sensitive than cardiovascular indices, the number of fluctuations within the mean SC per second (NFSC) showed a significant correlation with intraoperative noxious stimuli and has been considered as a possible measurement for postoperative pain. The severity of postoperative pain was found to significantly influence SC for pain assessment in the PACU. ${ }^{25}$ Despite moderate sensitivity and specificity, NFSC identified time points with moderateto-severe postoperative pain. ${ }^{26}$ NFSC accurately predicted the absence of moderate-to-severe pain in postoperative pediatric patients (1-16 years), but correlated weakly with NRS pain scores, being not specific for postoperative pain intensity and unable to identify analgesia requirements when compared with self-report measures in school-aged children after surgery. ${ }^{27}$ NFSC was found to fail to distinguish pain from other stressors in patients in the PACU as well. ${ }^{28}$ Others found that parameters of SC device (such as electrode type and sampling time) influence the accuracy of NFSC to identify states of moderate or severe postoperative pain. ${ }^{29}$ The inconsistencies of these results may be caused by the influences of other factors (stressors such as nausea, vomiting, and anxiety and medication such as neuromuscular reversal agents and alpha- 2 agonists) and the differences of device parameters. Further studies are required to standardize the device parameters and exclude the inappropriate proportion of patients for NFSC application.

\section{Pupillometry}

With more sensitive and specific advantages over other autonomic responses to pain (such as blood pressure and heart rate), pupillary diameter (PD) and pupillary light reflex 
amplitude (PLRA, the difference between PD before and after light stimulation) may be used to assess acute pain. It was found that the pupillary dilation response can be used as a measure of pain, although only in controlled situations when confounding factors are well controlled. ${ }^{30}$ However, it was found that acute postoperative pain was not associated with PD or PLRA, ${ }^{31}$ and PD is not significantly influenced by early postoperative pain or pain relief in the PACU because of a residual effect of intraoperative opioids and a level of nociceptive stimulation lower than in surgical conditions. ${ }^{32}$ Another study demonstrated that pupillometry may be used to predict pain during the procedure to adjust analgesia before noxious procedures in patients unable to communicate verbally in the intensive care unit (ICU). ${ }^{33}$ More studies are needed to confirm pupillometry's related utility in the very population that would benefit most and exclude the effects of other factors besides pain on the results.

\section{Management of postoperative pain in the PACU}

The WHO recommends a multimodal approach to the treatment of pain. ${ }^{34}$ Currently, a multimodal approach to postoperative analgesia is recommended as well, which has been integrated into more effective postoperative rehabilitation pathways with multidisciplinary collaboration, such as enhanced recovery after surgery (ERAS) and "fast tracks." With the combination of analgesic drugs and/or techniques, a multimodal strategy focuses on principles to allow early mobilization, early enteral nutrition, education, and attenuation of postoperative stress response. Psychological therapy and other complementary therapies are beneficial as well. Different surgeries result in different severity of pain and analgesic requirements, and a specific approach may have different effects on patients undergoing different surgeries. Therefore, procedure-specific and individual analgesic strategies are required. ${ }^{35}$

Targeting on central sensitization, preventive analgesia may be beneficial for reducing incidence and severity of both acute and chronic postoperative pain. As a part of preventive analgesia, preemptive analgesia involves the preoperative administration of analgesics so that they are effective intraoperatively, preventing central sensitization before exposure to painful stimuli. ${ }^{9}$ Preventive analgesia involves a broader approach for the entire perioperative period by blocking the neural transmission of all noxious perioperative stimuli. Although limited by methodologic issues that cause equivocalities, preemptive analgesia's efficacies have been supported and more widely accepted. ${ }^{9}$ To a certain degree, all the appropriate perioperative medication for postoperative analgesia, including preventive analgesia, can be considered as parts of postoperative pain management in the PACU.

\section{Pharmacological management Opioids}

Opioid analgesics are one of the cornerstone options for postoperative pain treatments with the advantage of no analgesic ceiling effects theoretically, but the analgesic efficacy of opioids is typically limited by the development of tolerance or opioid-related side effects realistically. ${ }^{36}$ Intravenous (IV) or intramuscular administration can be used for the treatment of moderate-to-severe pain. In addition to traditional administration routes, more options can be applied in the PACU. As compared with being instilled over the intact epidural space, $5 \mathrm{mg}$ morphine $(1 \mathrm{mg} / \mathrm{mL})$ soaked in gelfoam placed in the epidural space significantly reduced PACU stay and analgesic consumption and prolonged the postoperative analgesia after spine surgery. ${ }^{37}$ Perineural fentanyl additive to local anesthetics, ropivacaine, reduced VAS score at 30 minutes after administration in the PACU, although not showing prominent enhancement of analgesic effect in the field of continuous femoral nerve block after total knee arthroplasty. ${ }^{38}$ However, when managing postoperative analgesic failure, it was found that patients who did not respond to reasonable doses of opioids (morphine, $10 \mathrm{mg}$, IV) in the PACU tended to be unresponsive to further opioids, and nonopioid analgesic techniques (such as regional anesthesia) should be considered early for these patients. ${ }^{39}$

The principle of opioid administration is to obtain the maximum analgesia without intolerable adverse effects. Most of the opioid-related adverse effects are dose dependent, with nausea and vomiting, respiratory depression, and excessive sedation requiring more attention during the PACU period. Appropriate monitoring and timely treatment for opioid-related side effects are essential. As compared with nonopioid analgesics (nefopam), fentanyl, when used in a patient-controlled analgesia (PCA) regimen, was correlated with significantly higher Rhodes index scores (assessing postoperative nausea and vomiting) from 30 minutes after PACU arrival to 24 hours after PACU discharge. ${ }^{40}$ It was found that supervised continuous positive airway pressure treatment early after bariatric surgery improves sleep-disordered breathing and ameliorates the respiratory-depressant effects of opioids without undue hemodynamic effects. ${ }^{41}$

New opioids are being developed with retained analgesic effects but minimized adverse effects as compared with traditional opioids. Tapentadol is both a $\mu$-opioid agonist 
and a norepinephrine reuptake inhibitor, indicated for the treatment of moderate-to-severe pain. Compared with oxycodone immediate release (IR), tapentadol IR had similar efficacy for pain after arthroscopic shoulder surgery, but with greater overall improvement. ${ }^{42}$ Single dose of tapentadol administrated an hour before general anesthesia induction was effective in reducing perioperative analgesic requirements and pain in the PACU without additional side effects. ${ }^{43}$ Despite its improved gastrointestinal tolerability, the oral route of tapentadol may limit its usage in the PACU, while preemptive application can be an alternative with cautions in patients who have taken monoamine oxidase inhibitors. ${ }^{44}$

Extended-release epidural morphine (EREM) is a singledose extended-release morphine injection into the epidural space at lumbar level, which provides good postoperative analgesia for a period of 48 hours, with no need for epidural catheterization. ${ }^{45}$ Combined with a femoral nerve block, EREM can provide comparable analgesia to patientcontrolled epidural analgesia (PCEA) and shorter PACU times in patients undergoing unilateral total knee replacement and be considered as a therapeutic equivalence to PCEA that may be more cost-effective. ${ }^{46}$ EREM is also found to be an effective alternative to conventional pain management techniques and may have a role in further enhancing the enhanced recovery program after colorectal surgery. ${ }^{47}$ However, more evidences should be obtained regarding EREM's risk of respiratory depression and indication for usage in the PACU. ${ }^{48}$ An iontophoretic transdermal system (ITS), when used for administering fentanyl for postoperative pain management, was associated with a better ease-of-care profile and greater ease of mobility. ${ }^{49}$

\section{Nonopioid analgesics}

Nonopioids are important components of multimodal analgesic regimen with additive or synergistic analgesia through various different mechanisms from that of opioids while reducing opioid-induced side effects, ${ }^{3}$ which can be used both effectively and safely for a short term in the PACU, although the combination of nonopioids is challenging for relatively little evidence showing its definite benefits, its side effects when used for a longer term having generally been ignored, and even fewer literature evaluating the role of combining more than two nonopioids. ${ }^{2,50,51}$

More IV formulations of these drugs with faster onset time and potentially higher plasma levels as compared with the oral form have been available recently, which extend their usage in the PACU. ${ }^{52,53} \mathrm{IV}$ acetaminophen use in ambulatory surgery decreased postoperative pain following operative procedures in the PACU, although not being associated with decreased PACU length of stay. ${ }^{54}$ IV acetaminophen administered 15 minutes before endotracheal intubation of general anesthesia for cesarean delivery reduced postoperative administration of meperidine and pain in the PACU, ${ }^{55}$ and $1000 \mathrm{mg}$ IV acetaminophen at the surgical incision closure provided additional benefit in terms of improved postoperative pain scores, fewer potential adverse events related to opioid use, and decreased use of opioids after knee or hip arthroplasty. ${ }^{56}$ The combination of IV ibuprofen and hydromorphone produced a strong synergistic analgesia on postoperative pain after breast surgery. ${ }^{57} \mathrm{IV}$ ketorolac was equivalently effective as fentanyl for postoperative pain management at 30 and 150 minutes postoperatively in outpatients, although fentanyl was more effective at 15 minutes. ${ }^{58}$ Perioperative use of IV ketorolac after laparoscopic gastric bypass surgery for morbid obesity helped provide an earlier discharge from the PACU and better outcomes. ${ }^{59}$ Preemptive analgesia using either ketorolac or parecoxib (IV, 30 minutes prior to incision) showed a significantly better early postoperative pain control in the PACU than the control group in patients undergoing lumbar spinal fusion. ${ }^{60}$

Gabapentin improves the analgesic efficacy of opioids and reduces opioid consumption, but with an increased incidence of side effects such as sedation and dizziness. In patients undergoing elective surgical procedures, gabapentin reduced postoperative pain scores, but at the cost of delayed discharge from the PACU due to decreased level of consciousness in a dose-dependent fashion. ${ }^{61}$ As shown in a meta-analysis, preoperative gabapentin was more beneficial in mastectomy and spinal, abdominal, and thyroid surgeries on reducing postoperative opioid consumption as compared with the less significant results from studies on some other surgeries. ${ }^{62}$ Although pregabalin is absorbed more rapidly than gabapentin, some studies found that pregabalin provides additional analgesia in a short term. Oral pregabalin $(300 \mathrm{mg})$ administered 4 hours before the induction of anesthesia reduced pain intensity and increased patient satisfaction in the PACU after abdominal hysterectomy without additional risk of side effects, but lower dose $(150 \mathrm{mg})$ did not exert effects better than placebo. ${ }^{63}$ However, a single preoperative dose of pregabalin $(150 \mathrm{mg})$ was found to reduce postoperative pain at rest and morphine consumption during the PACU period after lumbar discectomy ${ }^{64}$ The inconsistency in these data may be caused by methodologic factors (including the difference between surgeries), which requires further studies.

Small-dose (analgesic) ketamine facilitates postoperative analgesia with its $N$-methyl-D-aspartate (NMDA) antagonist 
properties, attenuating central sensitization and opioid tolerance, although exerting possible amnestic effects. Ketamine supplemented intraoperatively produced better analgesia and decreased analgesic consumption after laparoscopic cholecystectomy in the PACU. ${ }^{65}$ Continuous $\mathrm{S}(+)$-ketamine infusion during laparoscopic cholecystectomy provided better postoperative pain control in the PACU than placebo. ${ }^{66}$ Racemic mixtures of ketamine are neurotoxic, the neuraxial use of which is strongly discouraged. In fact, a recent study revealed that the addition of ketamine $(1 \mathrm{mg} / \mathrm{kg})$ to $0.1 \%$ ropivacaine via continuous femoral block with pump infusion after repairing anterior cruciate ligament could not improve postoperative pain control. ${ }^{67}$

\section{Other adjuncts}

Dexmedetomidine (DEX) has been found to relieve postoperative pain and reduce postoperative opioid consumption in many surgical settings via various routes. ${ }^{68}$ Intraoperative administration of DEX could reduce perioperative and PACU opioid consumption as well as postoperative pain intensity in the PACU after neurosurgery. ${ }^{69}$ IV DEX was proved effective for preventing emergence agitation and reducing severe pain and the requirement of rescue drugs in the PACU in children. ${ }^{70}$ IV DEX at sedative doses initiated at the end of main procedures of the surgery to the time in the PACU resulted in better postoperative hemodynamic stability than fentanyl or remifentanil with a similar effect of pain control in the PACU. ${ }^{71}$ DEX as an intrathecal adjuvant with ropivacaine for spinal anesthesia provided better postoperative analgesia after infraumbilical surgeries as compared with $\mathrm{MgSO}_{4} \cdot{ }^{72}$ DEX as an epidural adjuvant had a greater analgesic and local anesthetic-sparing effect, compared with fentanyl, in the early postoperative period in children undergoing major orthopedic lower extremity surgery. ${ }^{73}$ The use of DEX as an adjunct to an ilioinguinal/iliohypogastric nerve block resulted in reduced pain following pediatric inguinal hernia repair in the PACU and a prolongation of the period to first supplemental analgesia demand. ${ }^{74}$ DEX local wound infiltration 5 minutes prior to skin incision significantly reduced perioperative (including PACU) fentanyl consumption, and subsequently ensured earlier discharge from PACU and less side effects. ${ }^{75}$ Perioperative usage of DEX has been used for postoperative analgesia, although heart rate needs to be monitored cautiously.

Perioperative usage of dexamethasone has been frequently studied for effective postoperative analgesia as well. A meta-analysis indicated that a single perioperative dose of dexamethasone (IV) had significant analgesic benefits with decreasing postoperative pain scores and opioid consumption, increasing time for the first dose of analgesic and shortening stays in the PACU. ${ }^{76}$ A single dose of dexamethasone (IV) 15 minutes before the induction of anesthesia enhanced ketamine's postoperative analgesic effects in children after tonsillectomy in the PACU. ${ }^{77}$ Low doses of dexamethasone (IV) administered at the time of block completion significantly prolonged the postoperative analgesic duration of single-shot interscalene block after arthroscopic shoulder surgery. ${ }^{78}$ Perineural dexamethasone added as an adjuvant of ropivacaine was more effective than IV in extending the duration of ropivacaine in interscalene brachial plexus blocks with lowering pain scores within 24 hours after surgery. ${ }^{79}$ Epidural dexamethasone added to bupivacaine also prolonged the duration of postoperative analgesia. ${ }^{80}$ Further studies are warranted to determine the optimal dosage with the minimized risk.

\section{Regional anesthesia techniques Epidural techniques}

Epidural analgesia (EA) has been widely used as a safe and effective method for the management of acute postoperative pain and even considered as the "gold standard" for pain management after major surgery for decades. ${ }^{2}$ Selection and dosage of analgesics, location of catheter placement, and onset and duration of administration should be taken into consideration when EA is planned. Local anesthetics, opioids, or the combinations of the two with (or without) adjuvant drugs can be used with single dose or continuous infusion with catheter for epidural administration. Continuous EA with local anesthetic-opioid combination is well accepted for excellent analgesia with fewer side effects. However, current evidence suggests that the advantages of EA may have been overestimated, and its risks have been underestimated in the past. As probably there are superior alternatives to EA, some other less invasive regional anesthesia techniques are comparably effective and safer. ${ }^{2}$

\section{Perineural techniques}

Perineural techniques can be applied in many parts of the body for postoperative analgesia with advantages over systemic opioids and neuraxial techniques for efficacy and less invasiveness, decreased opioid-related side effects and risk for spinal hematoma, and improvement in patient satisfaction. Single-injection peripheral nerve block is limited by relatively short duration. Continuous infusions of analgesics can be administered through peripheral nerve catheters allowing prolonged analgesia. Continuous perineural techniques 
are even recommended as the preferred choice for major orthopedic surgical procedures such as hip or knee replacement surgery. ${ }^{81}$

The efficacy and safety of perineural techniques for postoperative analgesia in the PACU have also been well established. A preoperative lumbar plexus block resulted in a reduction in pain scores in patients undergoing total hip arthroplasty in the immediate postoperative period in the PACU. ${ }^{82}$ Supplemental single-shot femoral nerve block for total hip arthroplasty resulted in earlier PACU discharge capability and better lung function and pain control postoperatively as well. ${ }^{83}$ When compared to ropivacaine $0.2 \%$ and bupivacaine $0.25 \%$, ropivacaine $0.5 \%$ for femoral nerve block provides superior postoperative analgesia in children undergoing arthroscopic knee surgery with decreased postoperative opioid consumption and earlier PACU/hospital discharge. ${ }^{84}$ Different procedures of continuous interscalene technique (out-of-plane vs in-plane technique) can offer equivalent analgesia as concerning PACU pain ratings, and out-ofplane technique can be an alternative method when in-plane approach is difficult to be performed on some patients. ${ }^{85}$ Ultrasound-guided interscalene nerve blocks for perioperative analgesia can be safely and effectively performed in obese patients with body mass index being associated with an increased peak PACU pain, PACU opioid administration, and incidence of PACU nausea. ${ }^{86}$

Paravertebral block (PVB) was as effective as thoracic epidural block (TEB) in pain control after thoracotomy, offered equivalent analgesia to either TEB or wound infiltration after cardiothoracic surgery, and reduced the risks of developing minor complications. ${ }^{87,88}$ Compared to general anesthesia, PVB for breast surgery reduced pain score at both rest and movement in the PACU, in addition to PVB's effects on improving pulmonary function and reducing length of hospital stay. ${ }^{89}$ Thoracic PVB reduced pain at rest and on cough after laparotomy in the PACU and appeared to be a promising analgesic technique for abdominal surgery in terms of efficacy and safety. ${ }^{90,91}$ Compared to the anatomic landmark-guided PVB, an ultrasound-guided PVB needed more local anesthetic, but there was no difference between the two approaches regarding perioperative opioid use, PACU pain scores, and complications; moreover, the latter one benefited better performance of junior physicians. ${ }^{92}$

First described in 2011, the pectoral nerve (Pecs) blocks have been used for analgesia for breast and chest wall procedures. ${ }^{93}$ When combined with general anesthesia, Pecs blocks lowered postoperative pain score, reduced postoperative opioid consumption, and decreased the length of PACU stay, as opposed to general anesthesia alone for breast surgery. ${ }^{94-96}$ Pecs improved the analgesic effects of thoracic PVB in the immediate postoperative period after reconstructive breast surgery. ${ }^{97}$ Pecs block was even found to provide superior postoperative analgesia than PVB after modified radical mastectomy (including lowering pain score in the initial postoperative 2 hours) without any adverse effect. ${ }^{98}$ More studies evaluating the safety of Pecs blocks offering data on its failure and complication rates are required.

Perineural techniques have not been used as frequently as supposed, ${ }^{99}$ but ultrasound guidances have improved the rate of correct identification of nerves and successful performance and reduced complications, which encourages their usages.

\section{Infiltrative techniques}

Being less invasive and easily to conduct, infiltrative techniques have received increasing attention. Used either alone or as part of multimodal regimens, these techniques have been proved to be effective and safe (with fewer opioid-related side effects) for postoperative pain management in the PACU.

Local subcutaneous anesthetic wound infiltration with $20 \mathrm{~mL}$ of $0.75 \%$ ropivacaine performed before carotid endarterectomy closure reduced the need for additional opioids, lowered the immediate postoperative pain, and improved alertness in PACU. ${ }^{100}$ As compared with bilateral superficial cervical plexus block, local wound infiltration could be equivalently effective for reducing pain scores and analgesic requirements during the immediate postoperative period in the PACU in patients who underwent robot-assisted endoscopic thyroidectomy ${ }^{101}$ Compared with a low-concentration and high-volume (125 $\mathrm{mL}$ ropivacaine $0.2 \%$ ) wound infiltration analgesia, a high-concentration and low-volume $(50 \mathrm{~mL}$ ropivacaine $0.5 \%$ ) one during cesarean delivery exerted equivalent effect on postoperative pain intensity and time spent in the PACU. ${ }^{102}$ Combination of intraperitoneal and incisional ropivacaine facilitated PACU transfer and effectively and safely reduced pain intensity after laparoscopic cholecystectomy as compared with the separate usage. ${ }^{103}$ Wound catheter infusions provide effective pain relief without major adverse effects, and the catheters can be placed in several sites, including subcutaneous, subfascial, preperitoneal, intraperitoneal, subacromial, intraosseous, and intra-articular..$^{99}$

Patients undergoing ileostomy reversal with transversus abdominis plane (TAP) blocks experienced less pain intensity and required fewer opioids in the PACU than those in the control group. ${ }^{104}$ Compared with the usage of IV fentanyl, unilateral TAP block with injection of bupivacaine reduced pain intensity, rescue analgesia, and time stay with less 
complications in the PACU in patients undergoing ureteric shock wave lithotripsy. ${ }^{105}$ However, although single-injection subcostal TAP block reduced morphine consumption from PACU admission to 6 hours as compared with IV opioid analgesia, it increased morphine consumption for 6-24 hours as compared with continuous thoracic EA after elective radical gastrectomy. ${ }^{106}$ Although the subcostal and posterior TAP had comparable effects on pain scores in the PACU initially, subcostal TAP block was better at lowering the scores than the posterior approach after 4 hours in patients undergoing laparoscopic cholecystectomy. ${ }^{107}$ A post-induction, pre-incision bilateral TAP block combined with local peritoneal infiltration at port sites with long-acting liposomal bupivacaine reduced initial and final PACU pain scores and shorten PACU times. ${ }^{108}$

Local infiltration analgesia (LIA) has achieved more widespread acceptance as a major recent development in lower-extremity joint replacement surgery. ${ }^{109}$ The LIA technique benefits postoperative pain relief safely as compared with traditional methods such as EA. ${ }^{110,111}$ More studies on the role of intra-articular catheters, optimization of analgesic combinations, and usage of ultra long-acting local anesthetics are required. Intraperitoneal use of local anesthetics during surgery was shown to reduce postoperative pain, opioids use, and the need for rescue analgesia as well. ${ }^{112}$

\section{PCA}

PCA is increasingly recognized as an ideal approach for postoperative pain management for its minimizing pharmacokinetic and pharmacodynamic variability in individual patients and providing significantly better analgesia and patient satisfaction. Multiple PCAs can be chosen for initiation in the PACU, including IV PCA, PCEA, patient-controlled regional analgesia (PCRA), patient-controlled intranasal analgesia (PCINA), patient-controlled transdermal analgesia (PCTA), and patientcontrolled sublingual analgesia (PCSA). Different agents, techniques, and/or their combinations enable more options of PCA. It should be cautious with the possible errors in the device, programming or by operators, in addition to the side effects of analgesics in PCA usage, and different regimens and administration/prevention strategies should be considered individually to minimize the adverse effects and enhance pain relief. ${ }^{113}$

\section{Consideration for special populations}

Mood disorders, such as anxiety and depression, and/or some personality types (e.g., neuroticism) may result in mental instabilities in the PACU, further complicate the postoperative pain perception and relief, and correlate with chronic PPP.
Preoperative interview and reassurance from anesthesiologists, midazolam, alpha-2 agonists, antidepressants, and anticonvulsants are effective in decreasing anxiety. ${ }^{114}$ Regarding linked mechanism of pain and depression, antidepressant drugs have been used for the prevention of acute postoperative pain, but there is insufficient evidence to support the routine use of them in the perioperative period. ${ }^{115,116}$ Antidepressants may not be appropriate for those with acute onset of depression perioperatively and/or rapid analgesia in the PACU, because these effects become apparent after using for a few days. There are rare studies on psychiatric medication in the PACU for the relatively short period, but some nonpharmacological therapies have shown potential benefits, such as psychological therapy, music, and aromatherapy. ${ }^{117}$ Psychological assessment and assistance from professionals should be considered if necessary. More studies on optimal analgesic strategies (the selection of measures and the timing of the intervention) for these patients in the PACU are needed.

Patients with opioid tolerance caused by the history of chronic pain with opioid-based analgesic therapy and/or a substance use disorder present more challenges. Additional considerations include preoperative identification of these patients, more objective assessment of pain, perioperative therapy with opioids with high intrinsic efficacy and/or higher dosage (without overdose), multimodal analgesia combined with nonopioid analgesics and/or regional techniques, NMDA receptor antagonists for attenuation of tolerance, preventing withdrawal syndromes, and psychological-social assistance. ${ }^{118-120}$ Larger doses of analgesic medication (in addition to the patients' baseline pain medication) are required in the immediate postoperative period, but analgesia is not frequently provided adequate enough. ${ }^{36}$ It was recommended to titrate opioids aggressively to achieve adequate pain control in the PACU. ${ }^{121}$ Initiation of PCA with IV opioids in the PACU minimized the risk of undermedication and breakthrough pain. ${ }^{122}$

\section{Acknowledgments}

This work was supported by the National Natural Science Foundation of China (Grant No. 81201053) and the China Scholarship Council (CSC No. 201608505030).

\section{Disclosure}

The authors report no conflicts of interest in this work.

\section{References}

1. The Lancet Commission on Global Surgery. Global surgery 2030: evidence and solutions for achieving health, welfare, and economic development. Available from: http://media.wix.com/ugd/346076_71 3dd3f8bb594739810d84c1928ef61a.pdf (or http://who.int/surgery/ en/). Accessed November 01, 2017. 
2. Rawal N. Current issues in postoperative pain management. Eur $J$ Anaesthesiol. 2016;33(3):160-171.

3. Wu CL, Raja SN. Treatment of acute postoperative pain. Lancet. 2011;377(9784):2215-2225.

4. Macrae WA. Chronic post-surgical pain: 10 years on. Br J Anaesth. 2008;101(1):77-86.

5. Kehlet H, Jensen TS, Woolf CJ. Persistent postsurgical pain: risk factors and prevention. Lancet. 2006;367(9522):1618-1625.

6. Sommer M, de Rijke JM, van Kleef M, et al. The prevalence of postoperative pain in a sample of 1490 surgical inpatients. Eur JAnaesthesiol. 2008;25(4):267-274.

7. Apfelbaum JL, Silverstein JH, Chung FF, et al. Practice guidelines for postanesthetic care: an updated report by the American Society of Anesthesiologists Task Force on Postanesthetic Care. Anesthesiology. 2013;118(2):291-307.

8. Pozek JP, Beausang D, Baratta JL, Viscusi ER. The acute to chronic pain transition: can chronic pain be prevented? Med Clin North Am. 2016;100(1):17-30.

9. Gupta A, Bhosale UA, Shah P, Yegnanarayan R, Sardesai S. Comparative pre-emptive analgesic efficacy study of novel antiepileptic agents lamotrigine and topiramate in patients undergoing major surgeries at a tertiary care hospital: a randomized double blind clinical trial. Ann Neurosci. 2016;23(3):162-170.

10. Hjermstad MJ, Fayers PM, Haugen DF, et al; European Palliative Care Research Collaborative (EPCRC). Studies comparing numerical rating scales, verbal rating scales, and visual analogue scales for assessment of pain intensity in adults: a systematic literature review. J Pain Symptom Manage. 2011;41(6):1073-1093.

11. Constant I, Sabourdin N. Monitoring depth of anesthesia: from consciousness to nociception. A window on subcortical brain activity. Paediatr Anaesth. 2015;25(1):73-82.

12. Masel EK, Huber P, Engler T, Watzke HH. Heart rate variability during treatment of breakthrough pain in patients with advanced cancer: a pilot study. J Pain Res. 2016;9:1215-1220.

13. Jensen EW, Valencia JF, Lopez A, et al. Monitoring hypnotic effect and nociception with two EEG-derived indices, qCON and qNOX, during general anaesthesia. Acta Anaesthesiol Scand. 2014;58(8):933-941.

14. Melia U, Gabarron E, Agusti M, et al. Comparison of the qCON and qNOX indices for the assessment of unconsciousness level and noxious stimulation response during surgery. J Clin Monit Comput. 2017;31(6):1273-1281.

15. Hamunen K, Kontinen V, Hakala E, Talke P, Paloheimo M, Kalso E. Effect of pain on autonomic nervous system indices derived from photoplethysmography in healthy volunteers. Br J Anaesth. 2012; 108(5):838-844.

16. Ling P, Siyuan Y, Wei W, Quan G, Bo G. Assessment of postoperative pain intensity by using photoplethysmography. $J$ Anesth. 2014;28(6):846-853.

17. Thee C, Ilies C, Gruenewald M, Kleinschmidt A, Steinfath M, Bein B. Reliability of the surgical Pleth index for assessment of postoperative pain: a pilot study. Eur J Anaesthesiol. 2015;32(1):44-48.

18. Ledowski T, Burke J, Hruby J. Surgical pleth index: prediction of postoperative pain and influence of arousal. Br J Anaesth. 2016;117(3):371-374.

19. Boselli E, Daniela-Ionescu M, Begou G, et al. Prospective observational study of the non-invasive assessment of immediate postoperative pain using the analgesia/nociception index (ANI). Br J Anaesth. 2013;111(3):453-459.

20. Szental JA, Webb A, Weeraratne C, Campbell A, Sivakumar H, Leong S. Postoperative pain after laparoscopic cholecystectomy is not reduced by intraoperative analgesia guided by analgesia nociception index (ANI(R)) monitoring: a randomized clinical trial. Br JAnaesth. 2015;114(4):640-645.

21. Boselli E, Bouvet L, Begou G, et al. Prediction of immediate postoperative pain using the analgesia/nociception index: a prospective observational study. Br J Anaesth. 2014;112(4):715-721.
22. Ledowski T, Tiong WS, Lee C, Wong B, Fiori T, Parker N. Analgesia nociception index: evaluation as a new parameter for acute postoperative pain. Br J Anaesth. 2013;111(4):627-629.

23. Gall O, Champigneulle B, Schweitzer B, et al. Postoperative pain assessment in children: a pilot study of the usefulness of the analgesia nociception index. Br J Anaesth. 2015;115(6):890-895.

24. Boselli E, Jeanne M. Analgesia/nociception index for the assessment of acute postoperative pain. Br J Anaesth. 2014;112(5): 936-937.

25. Ledowski T, Bromilow J, Paech MJ, Storm H, Hacking R, Schug SA. Monitoring of skin conductance to assess postoperative pain intensity. Br J Anaesth. 2006;97(6):862-865.

26. Ledowski T, Ang B, Schmarbeck T, Rhodes J. Monitoring of sympathetic tone to assess postoperative pain: skin conductance vs surgical stress index. Anaesthesia. 2009;64(7):727-731.

27. Choo EK, Magruder W, Montgomery CJ, Lim J, Brant R, Ansermino JM. Skin conductance fluctuations correlate poorly with postoperative self-report pain measures in school-aged children. Anesthesiology. 2010;113(1):175-182.

28. Czaplik M, Hubner C, Kony M, et al. Acute pain therapy in postanesthesia care unit directed by skin conductance: a randomized controlled trial. PLoS One. 2012;7(7):e41758.

29. Ledowski T, Albus S, Stein J, Macdonald B. Skin conductance for monitoring of acute pain in adult postoperative patients: influence of electrode surface area and sampling time. J Clin Monit Comput. 2011;25(6):371-376.

30. Larson MD, Sessler DI. Pupillometry to guide postoperative analgesia. Anesthesiology. 2012;116(5):980-982.

31. Kantor E, Montravers P, Longrois D, Guglielminotti J. Pain assessment in the postanaesthesia care unit using pupillometry: a crosssectional study after standard anaesthetic care. Eur J Anaesthesiol. 2014;31(2):91-97.

32. Duale C, Julien H, Pereira B, Abbal B, Baud C, Schoeffler P. Pupil diameter during postanesthetic recovery is not influenced by postoperative pain, but by the intraoperative opioid treatment. JClin Anesth. 2015;27(1):23-32.

33. Lukaszewicz AC, Dereu D, Gayat E, Payen D. The relevance of pupillometry for evaluation of analgesia before noxious procedures in the intensive care unit. Anesth Analg. 2015;120(6):1297-1300.

34. Zech DF, Grond S, Lynch J, Hertel D, Lehmann KA. Validation of World Health Organization Guidelines for cancer pain relief: a 10-year prospective study. Pain. 1995;63(1):65-76.

35. Lam DM, Choi SW, Wong SS, Irwin MG, Cheung CW. Efficacy of pregabalin in acute postoperative pain under different surgical categories: a meta-analysis. Medicine (Baltimore). 2015;94(46):e1944.

36. Hurley RW, Murphy JD, Wu CL. Chapter 98, acute postoperative pain. In: Miller RD, Cohen NH, Eriksson LI, Fleisher LA, Wiener-Kronish JP, Young WL, editors. Miller's Anesthesia. 8th ed. Philadelphia: Elsevier; 2015:2974-2998.

37. Kundra S, Gupta V, Bansal H, Grewal A, Katyal S, Choudhary AK Comparative study of epidural application of morphine versus gelfoam soaked in morphine for lumbar laminectomy. J Anaesthesiol Clin Pharmacol. 2014;30(1):46-52.

38. Heo BH, Lee HJ, Lee HG, et al. Femoral nerve block for patient undergoing total knee arthroplasty: prospective, randomized, doubleblinded study evaluating analgesic effect of perineural fentanyl additive to local anesthetics. Medicine (Baltimore). 2016;95(36):e4771.

39. Byrne K, Nolan A, Barnard J, Tozer M, Harris D, Sleigh J. Managing postoperative analgesic failure: tramadol versus morphine for refractory pain in the post-operative recovery unit. Pain Med. 2017;18(2):348-355.

40. Oh CS, Jung E, Lee SJ, Kim SH. Effect of nefopam- versus fentanylbased patient-controlled analgesia on postoperative nausea and vomiting in patients undergoing gynecological laparoscopic surgery: a prospective double-blind randomized controlled trial. Curr Med Res Opin. 2015;31(8):1599-1607. 
41. Zaremba S, Shin $\mathrm{CH}$, Hutter MM, et al. Continuous positive airway pressure mitigates opioid-induced worsening of sleepdisordered breathing early after bariatric surgery. Anesthesiology. 2016;125(1):92-104.

42. Vorsanger GJ, Klopfer AM, Xiang J, Benson CJ, Moskovitz BL, Rosenthal NR. Immediate-release tapentadol or oxycodone for treatment of acute postoperative pain after elective arthroscopic shoulder surgery: a randomized, phase IIIb study. J Opioid Manag. 2013;9(4):281-290.

43. Yadav G, Jain G, Samprathi A, Baghel A, Singh DK. Role of preemptive tapentadol in reduction of postoperative analgesic requirements after laparoscopic cholecystectomy. J Anaesthesiol Clin Pharmacol. 2016;32(4):492-496

44. Vadivelu N, Huang Y, Mirante B, et al. Patient considerations in the use of tapentadol for moderate to severe pain. Drug Healthc Patient Saf. 2013;5:151-159.

45. Mugabure Bujedo B. A clinical approach to neuraxial morphine for the treatment of postoperative pain. Pain Res Treat. 2012;2012:612145.

46. Sugar SL, Hutson LR Jr, Shannon P, Thomas LC, Nossaman BD. Comparison of extended-release epidural morphine with femoral nerve block to patient-controlled epidural analgesia for postoperative pain control of total knee arthroplasty: a case-controlled study. Ochsner J. 2011;11(1):17-21.

47. Peravali R, Brock R, Bright E, Mills P, Petty D, Alberts J. Enhancing the enhanced recovery program in colorectal surgery - use of extended-release epidural morphine (DepoDur(R)). Ann Coloproctol. 2014;30(4):186-191.

48. Horlocker TT, Burton AW, Connis RT, et al. Practice guidelines for the prevention, detection, and management of respiratory depression associated with neuraxial opioid administration. Anesthesiology. 2009;110(2):218-230.

49. Hartrick CT, Pestano CR, Ding L, Danesi H, Jones JB. Patient considerations in the use of transdermal iontophoretic fentanyl for acute postoperative pain. J Pain Res. 2016;9:215-222.

50. Mathiesen O, Thomsen BA, Kitter B, Dahl JB, Kehlet H. Need for improved treatment of postoperative pain. Dan MedJ. 2012;59(4):A4401.

51. Joshi GP, Schug SA, Kehlet H. Procedure-specific pain management and outcome strategies. Best Pract Res Clin Anaesthesiol. 2014; 28(2):191-201.

52. Bookstaver PB, Miller AD, Rudisill CN, Norris LB. Intravenous ibuprofen: the first injectable product for the treatment of pain and fever. J Pain Res. 2010;3:67-79.

53. Moller PL, Sindet-Pedersen S, Petersen CT, Juhl GI, Dillenschneider A, Skoglund LA. Onset of acetaminophen analgesia: comparison of oral and intravenous routes after third molar surgery. Br J Anaesth. 2005;94(5):642-648.

54. Khobrani MA, Camamo JM, Patanwala AE. Effect of intravenous acetaminophen on post-anesthesia care unit length of stay, opioid consumption, pain, and analgesic drug costs after ambulatory surgery. P T. 2017;42(2):125-139.

55. Soltani G, Molkizadeh A, Amini S. Effect of intravenous acetaminophen (paracetamol) on hemodynamic parameters following endotracheal tube intubation and postoperative pain in caesarian section surgeries. Anesth Pain Med. 2015;5(6):e30062.

56. Gupta A, Abubaker H, Demas E, Ahrendtsen L. A randomized trial comparing the safety and efficacy of intravenous ibuprofen versus ibuprofen and acetaminophen in knee or hip arthroplasty. Pain Physician. 2016;19(6):349-356.

57. Oh E, Ahn HJ, Sim WS, Lee JY. Synergistic effect of intravenous ibuprofen and hydromorphone for postoperative pain: prospective randomized controlled trial. Pain Physician. 2016;19(6):341-348.

58. Twersky RS, Lebovits A, Williams C, Sexton TR. Ketorolac versus fentanyl for postoperative pain management in outpatients. Clin J Pain. 1995;11(2):127-133.

59. Govindarajan R, Ghosh B, Sathyamoorthy MK, et al. Efficacy of ketorolac in lieu of narcotics in the operative management of laparoscopic surgery for morbid obesity. Surg Obes Relat Dis. 2005;1(6):530-535; discussion 535-536.
60. Siribumrungwong K, Cheewakidakarn J, Tangtrakulwanich B, Nimmaanrat $\mathrm{S}$. Comparing parecoxib and ketorolac as preemptive analgesia in patients undergoing posterior lumbar spinal fusion: a prospective randomized double-blinded placebo-controlled trial. BMC Musculoskelet Disord. 2015;16:59.

61. Siddiqui NT, Yousefzadeh A, Yousuf M, Kumar D, Choudhry FK, Friedman $\mathrm{Z}$. The effect of gabapentin on delayed discharge from the postanesthesia care unit: a retrospective analysis. Pain Pract. Epub 2017.

62. Arumugam S, Lau CS, Chamberlain RS. Use of preoperative gabapentin significantly reduces postoperative opioid consumption: a metaanalysis. J Pain Res. 2016;9:631-640.

63. Yucel A, Ozturk E, Aydogan MS, Durmus M, Colak C, Ersoy MO. Effects of 2 different doses of pregabalin on morphine consumption and pain after abdominal hysterectomy: a randomized, double-blind clinical trial. Curr Ther Res Clin Exp. 2011;72(4):173-183.

64. Spreng UJ, Dahl V, Raeder J. Effect of a single dose of pregabalin on post-operative pain and pre-operative anxiety in patients undergoing discectomy. Acta Anaesthesiol Scand. 2011;55(5):571-576.

65. Karcioglu M, Davarci I, Tuzcu K, et al. Addition of ketamine to propofol-alfentanil anesthesia may reduce postoperative pain in laparoscopic cholecystectomy. Surg Laparosc Endosc Percutan Tech. 2013;23(2):197-202.

66. Miziara LE, Simoni RF, Esteves LO, Cangiani LH, Grillo-Filho GF, Paula AG. Efficacy of continuous S(+)-ketamine infusion for postoperative pain control: a randomized placebo-controlled trial. Anesthesiol Res Pract. 2016;2016:6918327.

67. Rahimzadeh P, Faiz SH, Ziyaeifard M, Niknam K. Effectiveness of adding ketamine to ropivacaine infusion via femoral nerve catheter after knee anterior cruciate ligament repair. J Res Med Sci. 2013;18(8):632-636.

68. Vadivelu N, Mitra S, Narayan D. Recent advances in postoperative pain management. Yale J Biol Med. 2010;83(1):11-25.

69. Liu Y, Liang F, Liu X, Shao X, Jiang N, Gan X. Dexmedetomidine reduces perioperative opioid consumption and postoperative pain intensity in neurosurgery: a meta-analysis. J Neurosurg Anesthesiol. Epub 2017.

70. Ni J, Wei J, Yao Y, Jiang X, Luo L, Luo D. Effect of dexmedetomidine on preventing postoperative agitation in children: a meta-analysis. PLoS One. 2015;10(5):e0128450.

71. Choi JW, Joo JD, Kim DW, et al. Comparison of an intraoperative infusion of dexmedetomidine, fentanyl, and remifentanil on perioperative hemodynamics, sedation quality, and postoperative pain control. J Korean Med Sci. 2016;31(9):1485-1490.

72. Makhni R, Attri JP, Jain P, Chatrath V. Comparison of dexmedetomidine and magnesium sulfate as adjuvants with ropivacaine for spinal anesthesia in infraumbilical surgeries and postoperative analgesia. Anesth Essays Res. 2017;11(1):206-210.

73. Park SJ, Shin S, Kim SH, et al. Comparison of dexmedetomidine and fentanyl as an adjuvant to ropivacaine for postoperative epidural analgesia in pediatric orthopedic surgery. Yonsei Med J. 2017;58(3):650-657.

74. Lundblad M, Marhofer D, Eksborg S, Lonnqvist PA. Dexmedetomidine as adjunct to ilioinguinal/iliohypogastric nerve blocks for pediatric inguinal hernia repair: an exploratory randomized controlled trial. Paediatr Anaesth. 2015;25(9):897-905.

75. Mandal D, Das A, Chhaule S, et al. The effect of dexmedetomidine added to preemptive ( $2 \%$ lignocaine with adrenaline) infiltration on intraoperative hemodynamics and postoperative pain after ambulatory maxillofacial surgeries under general anesthesia. Anesth Essays Res. 2016;10(2):324-331.

76. Waldron NH, Jones CA, Gan TJ, Allen TK, Habib AS. Impact of perioperative dexamethasone on postoperative analgesia and side-effects: systematic review and meta-analysis. Br JAnaesth. 2013;110(2):191-200.

77. Safavi M, Honarmand A, Habibabady MR, Baraty S, Aghadavoudi O. Assessing intravenous ketamine and intravenous dexamethasone separately and in combination for early oral intake, vomiting and postoperative pain relief in children following tonsillectomy. Med Arh. 2012;66(2):111-115. 
78. Chalifoux F, Colin F, St-Pierre P, Godin N, Brulotte V. Low dose intravenous dexamethasone $(4 \mathrm{mg}$ and $10 \mathrm{mg}$ ) significantly prolongs the analgesic duration of single-shot interscalene block after arthroscopic shoulder surgery: a prospective randomized placebo-controlled study. Can J Anaesth. 2017;64(3):280-289.

79. Sakae TM, Marchioro P, Schuelter-Trevisol F, Trevisol DJ. Dexamethasone as a ropivacaine adjuvant for ultrasound-guided interscalene brachial plexus block: a randomized, double-blinded clinical trial. J Clin Anesth. 2017;38:133-136.

80. Razavizadeh MR, Fazel MR, Heydarian N, Atoof F. Epidural dexamethasone for postoperative analgesia in patients undergoing unilateral inguinal herniorrhaphy: a comparative study. Pain Res Manag. 2017;2017:7649458

81. Fowler SJ, Symons J, Sabato S, Myles PS. Epidural analgesia compared with peripheral nerve blockade after major knee surgery: a systematic review and meta-analysis of randomized trials. Br J Anaesth. 2008;100(2):154-164.

82. Goytizolo EA, Stundner O, Rua SH, et al. The effect of regional analgesia on vascular tone in hip arthroplasty patients. HSS J 2016;12(2):125-131.

83. Wiesmann T, Steinfeldt T, Wagner G, Wulf H, Schmitt J, Zoremba M. Supplemental single shot femoral nerve block for total hip arthroplasty: impact on early postoperative care, pain management and lung function. Minerva Anestesiol. 2014;80(1):48-57.

84. Veneziano G, Tripi J, Tumin D, et al. Femoral nerve blockade using various concentrations of local anesthetic for knee arthroscopy in the pediatric population. J Pain Res. 2016;9:1073-1079.

85. Schwenk ES, Gandhi K, Baratta JL, et al. Ultrasound-guided out-ofplane vs. in-plane interscalene catheters: a randomized, prospective study. Anesth Pain Med. 2015;5(6):e31111.

86. Schroeder K, Andrei AC, Furlong MJ, Donnelly MJ, Han S, Becker AM. The perioperative effect of increased body mass index on peripheral nerve blockade: an analysis of 528 ultrasound guided interscalene blocks. Rev Bras Anestesiol. 2012;62(1):28-38.

87. Yeung JH, Gates S, Naidu BV, Wilson MJ, Gao Smith F. Paravertebral block versus thoracic epidural for patients undergoing thoracotomy. Cochrane Database Syst Rev. 2016;2:CD009121.

88. Scarfe AJ, Schuhmann-Hingel S, Duncan JK, Ma N, Atukorale YN, Cameron AL. Continuous paravertebral block for post-cardiothoracic surgery analgesia: a systematic review and meta-analysis. Eur J Cardiothorac Surg. 2016;50(6):1010-1018.

89. Sundarathiti P, von Bormann B, Suvikapakornkul R, Lertsithichai $\mathrm{P}$, Arnuntasupakul V. Paravertebral catheter for three-level injection in radical mastectomy: a randomised controlled study. PLoS One 2015;10(6):e0129539.

90. Liu F, Zhang H, Zuo Y. Bilateral thoracic paravertebral block for immediate postoperative pain relief in the PACU: a prospective, observational study. BMC Anesthesiol. 2017;17(1):89.

91. El-Boghdadly K, Madjdpour C, Chin KJ. Thoracic paravertebral blocks in abdominal surgery - a systematic review of randomized controlled trials. Br J Anaesth. 2016;117(3):297-308.

92. Saran JS, Hoefnagel AL, Skinner KA, Feng C, Smith DI. Comparison of single-injection ultrasound-guided approach versus multilevel landmark-based approach for thoracic paravertebral blockade for breast tumor resection: a retrospective analysis at a tertiary care teaching institution. J Pain Res. 2017;10:1487-1492.

93. Blanco R. The 'pecs block': a novel technique for providing analgesia after breast surgery. Anaesthesia. 2011;66(9):847-848.

94. Bashandy GM, Abbas DN. Pectoral nerves I and II blocks in multimodal analgesia for breast cancer surgery: a randomized clinical trial. Reg Anesth Pain Med. 2015;40(1):68-74.

95. Wang K, Zhang X, Zhang T, et al. The efficacy of ultrasound-guided type II pectoral nerve blocks in perioperative pain management for immediate reconstruction after modified radical mastectomy. A prospective, randomized study. Clin J Pain. Epub 2017
96. Versyck B, van Geffen GJ, Van Houwe P. Prospective double blind randomized placebo-controlled clinical trial of the pectoral nerves (Pecs) block type II. J Clin Anesth. 2017;40:46-50.

97. Sopena-Zubiria LA, Fernandez-Mere LA, Valdes Arias C, Munoz Gonzalez F, Sanchez Asheras J, Ibanez Ernandez C. [Thoracic paravertebral block compared to thoracic paravertebral block plus pectoral nerve block in reconstructive breast surgery]. Rev Esp Anestesiol Reanim. 2012;59(1):12-17.

98. Kulhari S, Bharti N, Bala I, Arora S, Singh G. Efficacy of pectoral nerve block versus thoracic paravertebral block for postoperative analgesia after radical mastectomy: a randomized controlled trial. $\mathrm{Br}$ J Anaesth. 2016;117(3):382-386.

99. Rawal N. American Society of Regional Anesthesia and Pain Medicine 2010 Gaston Labat Lecture: perineural catheter analgesia as a routine method after ambulatory surgery--effective but unrealistic. Reg Anesth Pain Med. 2012;37(1):72-78.

100. Cherprenet AL, Rambourdin-Perraud M, Laforet S, et al. Local anaesthetic infiltration at the end of carotid endarterectomy improves postoperative analgesia. Acta Anaesthesiol Scand. 2015;59(1):107-114.

101. Shin S, Chung WY, Jeong JJ, Kang SW, Oh YJ. Analgesic efficacy of bilateral superficial cervical plexus block in robot-assisted endoscopic thyroidectomy using a transaxillary approach. World J Surg. 2012;36(12):2831-2837.

102. Larsen KR, Kristensen BB, Rasmussen MA, et al. Effect of highvolume systematic local infiltration analgesia in Caesarean section: a randomised, placebo-controlled trial. Acta Anaesthesiol Scand. 2015;59(5):632-639.

103. Liu DS, Guan F, Wang B, Zhang T. Combined usage with intraperitoneal and incisional ropivacaine reduces pain severity after laparoscopic cholecystectomy. Int J Clin Exp Med. 2015;8(12):22460-22468

104. Amlong CA, Schroeder KM, Andrei AC, Han S, Donnelly MJ. The analgesic efficacy of transversus abdominis plane blocks in ileostomy takedowns: a retrospective analysis. J Clin Anesth. 2012;24(5):373-377.

105. Elnabtity AM, Tawfeek MM, Keera AA, Badran YA. Is unilateral transversus abdominis plane block an analgesic alternative for ureteric shock wave lithotripsy? Anesth Essays Res. 2015;9(1):51-56.

106. Wu Y, Liu F, Tang H, et al. The analgesic efficacy of subcostal transversus abdominis plane block compared with thoracic epidural analgesia and intravenous opioid analgesia after radical gastrectomy. Anesth Analg. 2013;117(2):507-513.

107. Bhatia N, Arora S, Jyotsna W, Kaur G. Comparison of posterior and subcostal approaches to ultrasound-guided transverse abdominis plane block for postoperative analgesia in laparoscopic cholecystectomy. J Clin Anesth. 2014;26(4):294-299.

108. Keller DS, Tahilramani RN, Flores-Gonzalez JR, Ibarra S, Haas EM. Pilot study of a novel pain management strategy: evaluating the impact on patient outcomes. Surg Endosc. 2016;30(6):2192-2198.

109. Rawal N. Local infiltration analgesia and other multicomponent techniques to improve postoperative outcome - are we comparing oranges and apples? Reg Anesth Pain Med. 2011;36(5):417-420.

110. Andersen KV, Bak M, Christensen BV, Harazuk J, Pedersen NA, Soballe K. A randomized, controlled trial comparing local infiltration analgesia with epidural infusion for total knee arthroplasty. Acta Orthop. 2010;81(5):606-610.

111. Spreng UJ, Dahl V, Hjall A, Fagerland MW, Raeder J. High-volume local infiltration analgesia combined with intravenous or local ketorolac+morphine compared with epidural analgesia after total knee arthroplasty. Br J Anaesth. 2010;105(5):675-682.

112. Kahokehr A, Sammour T, Srinivasa S, Hill AG. Systematic review and meta-analysis of intraperitoneal local anaesthetic for pain reduction after laparoscopic gastric procedures. Br J Surg. 2011;98(1):29-36.

113. Koh JC, Song Y, Kim SY, Park S, Ko SH, Han DW. Postoperative pain and patient-controlled epidural analgesia-related adverse effects in young and elderly patients: a retrospective analysis of 2,435 patients. J Pain Res. 2017;10:897-904. 
114. Sheen MJ, Chang FL, Ho ST. Anesthetic premedication: new horizons of an old practice. Acta Anaesthesiol Taiwan. 2014;52(3):134-142.

115. Ghoneim MM, O'Hara MW. Depression and postoperative complications: an overview. BMC Surg. 2016;16:5.

116. Wong K, Phelan R, Kalso E, et al. Antidepressant drugs for prevention of acute and chronic postsurgical pain: early evidence and recommended future directions. Anesthesiology. 2014;121(3):591-608.

117. Matsota P, Christodoulopoulou T, Smyrnioti ME, et al. Music's use for anesthesia and analgesia. J Altern Complement Med. 2013; 19(4):298-307.

118. Wenzel JT, Schwenk ES, Baratta JL, Viscusi ER. Managing opioidtolerant patients in the perioperative surgical home. Anesthesiol Clin. 2016;34(2):287-301.
119. Huxtable CA, Roberts LJ, Somogyi AA, MacIntyre PE. Acute pain management in opioid-tolerant patients: a growing challenge. Anaesth Intensive Care. 2011;39(5):804-823.

120. Vadivelu N, Kai AM, Kodumudi V, Zhu R, Hines R. Pain management of patients with substance abuse in the ambulatory setting. Curr Pain Headache Rep. 2017;21(2):9.

121. Carroll IR, Angst MS, Clark JD. Management of perioperative pain in patients chronically consuming opioids. Reg Anesth Pain Med. 2004;29(6):576-591.

122. Mitra S, Sinatra RS. Perioperative management of acute pain in the opioid-dependent patient. Anesthesiology. 2004;101(1):212-227.

\section{Publish your work in this journal}

The Journal of Pain Research is an international, peer reviewed, open access, online journal that welcomes laboratory and clinical findings in the fields of pain research and the prevention and management of pain. Original research, reviews, symposium reports, hypothesis formation and commentaries are all considered for publication.

\section{Dovepress}

The manuscript management system is completely online and includes a very quick and fair peer-review system, which is all easy to use. Visit http://www.dovepress.com/testimonials.php to read real quotes from published authors. 